\title{
La república perdida de Santos Guayama. Demandas indígenas y rebeliones montoneras en Argentina, siglo XIX
}

\section{The Santos Guayama's lost republic. Indigenous demands and montonero rebellions in Argentina, XIX century}

\section{Diego Escolar ${ }^{1}$}

\begin{abstract}
Resumen
Centrado en la figura del caudillo Santos Guayama, este artículo analiza la influencia de demandas y tradiciones políticas indígenas de origen colonial en las rebeliones montoneras federales de las décadas de 1860 y 1870 en el oeste argentino. La historiografía argentina no tomó en cuenta la existencia de experiencias étnicas como factores en algunos casos decisivos de la movilización política del período. Sin embargo, recientes hallazgos documentales sobre el área de Guanacache, en el centro de la región, y una nueva relectura de los procesos, sugieren una estrecha relación de estos conflictos con tradiciones políticas indígenas de lucha por la tierra de antiguas reducciones.
\end{abstract}

Palabras claves: huarpes, montoneras, Santos Guayama, formación del Estado, Argentina.

\begin{abstract}
Centered in the caudillo Santos Guayama, this article analyses the impact of indigenous political traditions on the federalist rebelions in the Argentinean west between 1860 and 1870 decades. The Argentinean historiography doesn't consider the significance of ethnic experiences as factors of political movilization during this period. But recent documental findings on Guanacache area, at the core of the region, suggest the close relationship of these conflicts with political indigenous traditions of land struggle from ancient reductions.
\end{abstract}

Keywords: Huarpes, Montoneras, Santos Guayama, State building.

Recibido: 12 mayo 2017. Aceptado: 21 septiembre 2017

1 CONICET-IANIGLA / Universidad Nacional de Cuyo Mendoza, ARGENTINA.

Email: descolar@gmail.com 


\section{Introducción}

Santos Guayama es un héroe histórico de las llanuras desérticas o travesías de la región argentina de Cuyo, al este de la cordillera de los Andes. Asociado a las insurrecciones montoneras que azotaron el país y la región en la segunda mitad del siglo XIX, su figura está asociada a narrativas de autonomía local, poder territorial y movilización campesina e indígena. Sin embargo para la región y el período, la historiografía no solo había desestimado agencia política subalterna sino que había decretado la ausencia de población o identidades indígenas.

La región de Cuyo, provincia de Chile hasta la creación del virreinato del Río de La Plata en 1776, estaba habitada por diversos grupos indígenas, principalmente los denominados huarpes. Según diversos cronistas la población total era de entre 20 mil y 100 mil personas, que en gran proporción fueron trasla- dados forzadamente al Valle Central y Norte Chico chilenos a lo largo de los siglos XVI y XVII. Debido a esto, y a una narrativa etnonacional de "blanqueamiento" (Escolar, 2007) este pueblo y por extensión toda la población indígena fue considerada extinta durante la conquista española (Canals Frau, 1946; Michieli, 1983; Prieto, 1976). Pero en las áreas rurales de Cuyo persistió una sorda lucha de los indígenas o sus descendientes por mantener el acceso a la tierra y el agua, crecientemente expropiada por los criollos. Guanacache, un amplio conjunto de lagunas y esteros formados por el desagüe en la llanura árida al este de la cordillera de los ríos Mendoza y San Juan, fue un lugar de refugio para los huarpes y otros grupos indígenas, además de un variopinto conjunto de excluidos y perseguidos de la sociedad colonial. En la segunda mitad del siglo XVIII obtienen el estatus de reducción indígena y durante el XIX mantuvieron una permanente lucha judicial y militar por sus tierras y autonomía.

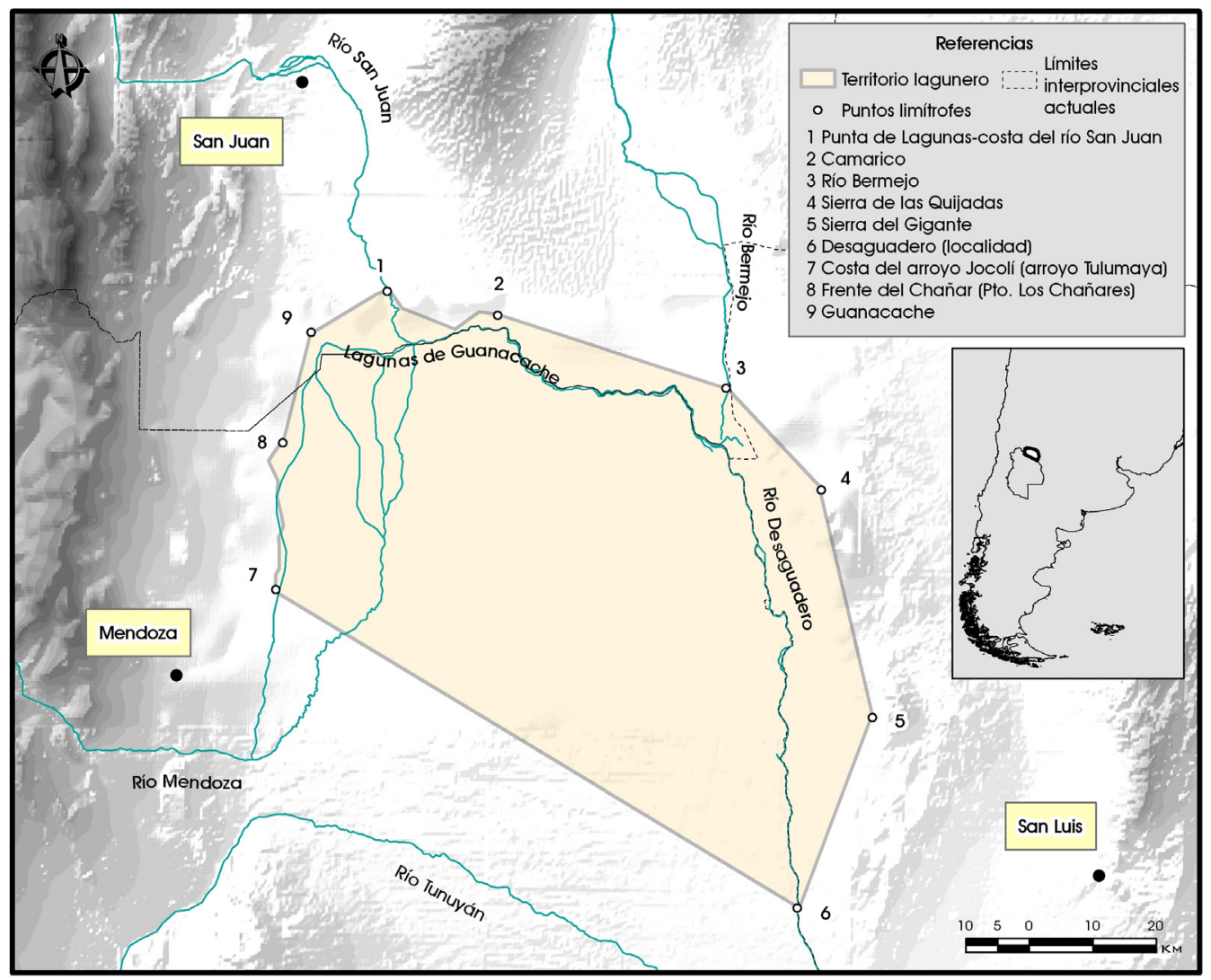

Figura 1. Territorio reclamado por los laguneros de Guanacache en la primera mitad del siglo XIX y su situación regional (elaboración del autor). 
Caracterizado como bandido, montonero o cacique justiciero, con base en las Lagunas de Guanacache, Guayama representó el momento más violento de un virtual estado insurreccional que, con interminables asaltos y guerrillas, desafió el control estatal en la campaña cuyana entre las décadas de 1860 y 1870. La literatura regional y los partes militares y policiales de su época, adjudicándole todo tipo de crímenes, alimentaron la imagen de un salvajismo sanguinario que calificaba declarar al caudillo "fuera de la ley de las naciones. Algunas piezas de ficción, pero sobre todo la narrativa oral popular, proporcionaron sin embargo una perspectiva más benigna que lo muestra como justiciero, distribuidor de bienes y defensor de un territorio indígena rebelde.

El caudillo fue una pieza política relevante en el convulsionado período de formación del Estado nacional. Habría integrado primero las montoneras de Ángel Vicente Peñaloza “el Chacho” durante las insurrecciones federales de $1862-1863^{2}$ y algunos testimonios sugieren que comandó el grueso de los montoneros desmovilizados luego de la derrota. ${ }^{3}$ Las primeras referencias documentadas señalan su participación entre 1866 y 1867, junto a Juan Saa y otros, en la Revolución de los Colorados en Cuyo que se integró con el levantamiento de Felipe Varela en Catamarca y La Rioja. Su famoso Batallón Laguneros fue una pieza clave en batallas como Pozo de Vargas y la toma de la ciudad de Salta, en 1867. Luego de la derrota de Felipe Varela, Guayama reunió los restos del ejército desmovilizado y en 1868, junto con Aurelio Zalazar y Sebastián Elizondo entre otros líderes, tomaron la ciudad de La Rioja. Después de una fallida negociación por un indulto y la incorporación como autoridades en departamentos

2 Carte, 1969; Chumbita, 2000.

3 En la Encuesta Nacional de Folklore de 1921 se recoge el testimonio de un octogenario según el cual "Guallama oficial de una tropa de gauchos estaba unido al Chacho, cuando lo matan a Peńaloza quedó Guallama al mando de toda la tropa. Estos hombres se dedicaban al saqueo de pueblos y tropas de carros". Encuesta $\mathrm{Na}$ cional de Folklore, San Juan, Carp. 140. El testimonio de un viajero afirma ese ańo que Santos Guallamas y Santos Abdón Fernández eran [...] muy conocidos por sus hazañas en la carrera de crímenes que han hecho durante las montoneras en estos últimos años". Archivo Histórico de Mendoza (en adelante AHM), carp. 699, Doc. 3. rurales, comenzó un ciclo de insurrecciones, asaltos y permanente persecución de Guayama que se agudizó entre 1869 y 1872 . Sus acciones se desarrollaron en todo Cuyo atacando haciendas, caravanas y arrías, y tomando pueblos y puestos fronterizos que comerciaban con Chile. Con un cuerpo variable de guerrillas reclutadas principalmente entre llanistos riojanos y laguneros (muchos de ellos antiguos montoneros, pero también desertores, peones, troperos y obreros viales) y con una red de importantes contactos políticos mantuvo hasta su muerte en 1879 el relativo control territorial de Guanacache y de buena parte de la campaña cuyana. Las Lagunas de Guanacache, entre las provincias de San Juan, Mendoza y San Luis, fueron el centro de sus operaciones y donde la saga de Guayama persistió con mayor fuerza hasta la actualidad.

Los relatos sobre Guayama están poblados de anécdotas donde los acentos más destacados son el carisma y seducción del caudillo, su generosidad para con los laguneros y la defensa de su territorio. En el área aún se conocen los lugares donde se refugiaba y existen muchas familias que se consideran sus descendientes. Su alma se considera milagrosa y se le hacen promesas para la recuperación de animales perdidos en el monte. La figura de San Roque en la capilla de Nuestra Señora del Rosario de Las Lagunas -un gaucho elegante con larga barba y vestido negros que es llevado en procesión junto con la Virgen en la fiesta patronal- representa a Santos Guayama ${ }^{4}$ y hay quienes afirman que su cadáver fue enterrado bajo otro nombre en el cementerio local.

Una de las características más notables de las narrativas sobre Guayama es su vinculación con una identidad indígena. En Las Lagunas, muchos le atribuyen la conducción de una lucha de resistencia de los huarpes contra la intromisión de los "ricos" de las ciudades. Las guerras civiles en la zona son leídas por Sixto Jofré, Juan Nylo Reynoso y otros como el momento en que los huarpes "hicieron pata ancha" para defenderse militarmente de la usurpación

4 La primera mención de este culto ha sido publicada por Quiroga Salcedo y González de Ortiz (1987). Según los laguneros, la adoración de San Roque y la misma estatua en madera habría disimulado el homenaje ritual a Guayama, por la fuerte represión de que eran objeto sus descendientes y seguidores. 
de sus tierras, iniciada con la conquista espańola y algunos añoran que en la actualidad "hubiera otro Guayama”.

Estas interpretaciones se inscriben en el proceso de reemergencia de identidades huarpes desde la década de 1990. En las tres provincias de Cuyo y en particular en Guanacache fueron reconocidas oficialmente hasta el momento una veintena de comunidades que demandan la restitución de sus territorios, la cual en algunos casos se concretó. La movilización huarpe ha apelado a Guayama como cacique y ancestro rescatando su papel en la defensa de las tierras durante el período más cruento de una larga historia colonial (Escolar, 2007, 2013, 2015). Hasta el momento, no obstante, la historia de Santos Guayama y la beligerancia popular en el área durante el siglo XIX no han sido consistentemente vinculadas con demandas e identidades indígenas. Desde la perspectiva de arqueólogos y etnohistoriadores locales, por su parte, éstas son consideradas invenciones oportunistas basadas en reelaboraciones muy imaginativas del pasado (García, 2004; Michieli, 2000). ${ }^{5}$

Este artículo propone conectar las acciones de Santos Guayama con una larga tradición de demandas y movilización política indígenas inspiradas en tradiciones republicanas y legitimadas no como reacción anárquica contra la dinámica de formación nacional sino como prácticas de construcción estatal. Confiamos en que este ejercicio permitirá comprender mejor la movilización política rural en Cuyo duran-

5 En algunos ensayos o piezas literarias el montonero fue inscripto como un tema pintoresco de la historia argentina (Siri, 1945; Funes, 1938; Carte, 1969; Quiroga de Yakin, 1971) y más recientemente como montonero libertario o bandido social (Chumbita, 1994, 1998, 2000; Concatti 2003). Chumbita, al igual que la narrativa oral y algunas aproximaciones literarias (Quiroga de Yakin, 1971; Concatti 2003) propuso una conexión entre las acciones del caudillo y una identidad o historia indígena. Pero estos aportes no contaron con un sustento documental o etnográfico capaz de constatarla, el principal de ellos, las demadas territoriales indígenas promovidas por los laguneros durante el siglo XIX. etnográfico capaz de constatarla deradaserrado bajo otro nombre en el cementerio local. etnográfico capaz de constatarla deradaserrado bajo otro nombre en el cementerio local. te el siglo XIX y también relativizar la neta división existente entre una historia "indígena” y otra "criolla” según la lectura aún predominante de las guerras civiles argentinas. ${ }^{6}$

La etnicidad no fue considerada por la historiografía académica como un factor relevante para explicar la movilización política del período. Sin embargo, algunos historiadores del siglo XIX ${ }^{7}$ señalaron como causa principal de las grandes rebeliones montoneras a la condición parcialmente indígena de la población rural subalterna. ${ }^{8}$ En esto seguían al político e intelectual cuyano Domingo Faustino Sarmiento, quien había abonado la idea de que la cultura y sobre todo la historia de despojos de tierras indígenas y el resentimiento colonial de sus descendientes era el motor de su persistente rebeldía (Escolar, 2007). Pero como regla general, se impuso en la historiografía una vehemente denegación de la posible continuidad de poblaciones indígenas, hecho que no fue ajeno tanto a la reproducción de la autoimagen blanca y europea de sus élites, capas medias, intelectuales y gran parte de los sectores populares, como a la legitimación de la apropiación de tierras campesinas e indígenas por parte de elites criollas, inmigrantes y burguesías urbanas desde el XIX hasta la

6 Los escasos análisis que proponen clivajes raciales y étnicos para explicar la movilización política en la región cuyana durante el siglo XIX, con variable aproximación son los de Ariel de la Fuente (2000), David Rock (1998), y Chumbita (1994, 1998, 2000). No obstante constituir un estímulo a las preguntas de esta investigación, no alcanzaron a demostrar una relación consistente con trayectorias políticas y demandas indígenas concretas.

7 Por ejemplo, Vicente Fidel López y José María Ramos Mejía (Fradkin, 2006, p. 16).

8 Ver Escolar, 2007. El punto ha sido retomado por Ariel de la Fuente (2007) y Hugo Chumbita (1998) en valiosos aportes que proveen información sobre las interpelaciones indígenas en La Rioja del siglo XIX, aunque sin alcanzar a vincular consistentemente la postulada condición o ascendencia indígena con proyectos, estrategias o una historia política indígena. El problema radica en parte en que se identifica la condición indígena con un sustrato racial y cultural y no como una producción activa, ligada básicamente a experiencias políticas. La pregunta más pertinente, en este sentido, no es tanto si había indios en las montoneras, sino en qué medida determinadas indigenidades fueron articuladas o desarticuladas históricamente por experiencias como los levantamientos montoneros. 
actualidad. Sin embargo, como ya hemos señalado para Cuyo, las proyecciones de identidad indígena o criolla han fluctuado y en épocas de rebelión o beligerancia popular las elites con frecuencia asociaron marcas o argumentos indígenas sobre los sectores subalternos (Escolar, 2007). La proyección de identidades indígenas vincularía en este sentido, más que con descripciones culturales, con argumentos políticos que asociarían indigenidad a ausencia de control o soberanía estatal sobre grupos de población.

La hipótesis que opera en nuestro análisis es que para las élites de la época, y en parte para la historiografía hasta el presente, la calificación indígena o criolla de la población dependió más de la evaluación implícita de su autonomía o soberanía respecto de las formaciones estatales, que de la presencia de características culturales o fenotípicas, o incluso de tradiciones y memorias colectivas indígenas, las cuales podían verificarse para poblaciones "dentro" y "fuera" de las fronteras. ${ }^{9}$ Recíprocamente, cuando los ideólogos del Estado Nacional en las décadas de 1860 y 1870 legitimaron la producción de la soberanía estatal efectiva hacia el interior del área "criolla" en las campañas de La Rioja, San Luis, San Juan y Mendoza, con frecuencia los "gauchos" o montoneras pasaron a ser indigenizados (Escolar, 2007). Las identidades de grupos como los laguneros de Cuyo fueron más polivalentes de lo que se ha supuesto desde los análisis históricos influidos tanto por nociones culturalistas como por las imaginaciones geoétnicas. Por ello es ocioso también considerar una política o identidad como "indígena" mediante el llano expediente de atribuir una condición indí-

9 Hernán Otero observó esta eficacia clasificatoria en los censos nacionales realizados a partir de 1869 (Otero, 2006). Desde la lógica censal desetnicizada de la "grilla liberal", quienes aparecen categorizados como indios no lo son a partir de una clasificación sociocultural o racial, sino exclusivamente por una condición política: indio es aquél que habita en el "desierto" y que, por tanto, escapa a todo control del Estado. En las provincias más antiguas (como Córdoba y Buenos Aires), por el contrario, la ausencia censal de "indios" derivó directamente de la consideración de la población como argentina (Otero, 2006: 343, 348). La clasificación (implícita) de los indígenas se basaba entonces en una "definición de base geopolítica y no étnica o antropológica [...] una vez operado el control sobre el desierto la población india sencillamente "desapareció" (Otero, 2006, 350)" gena primordial (étnica, racial, etc.) a los sujetos que la protagonizan. La indigenidad en Guanacache no fue un fundamento previo que definía la identidad de los sujetos, sino una producción activa que se generó, reformuló y reconfiguró a través de los conflictos, tanto desde los propios sujetos como desde los discursos de sus antagonistas. Tales clasificaciones estuvieron ligadas, más que a un "contenido" cultural, a luchas y evaluaciones políticas con relación al proceso de formación del Estado y la legitimidad de la propiedad de la tierra.

\section{Tierras indígenas y formación del Estado en Guanacache}

Una circunstancia desconocida hasta hace muy poco es que durante los siglos XIX y XX se produjeron en el área demandas por la propiedad comunal de la tierra por parte de grupos que se identificaban como indígenas y esgrimían un pasado reduccional (Escolar, 2007, 2013, 2015). Los laguneros de Guanacache lograron no solo que se atendieran sus reclamos sino incluso que un gobierno provincial reinstaurara en pleno período independiente el cargo colonial del Protector de Indios hasta la década de 1850, mostrando poseer una capacidad de agencia política capaz no solo de promover sus reclamos, sino de generar transformaciones en el propio Estado para inscribir sus derechos. El caso desmiente además el extendido postulado de extinción de las sociedades indígenas en la Argentina "criolla" durante la primera mitad del siglo XIX que está siendo revisado también para otras áreas. ${ }^{10}$ Estudios recientes muestran que a pesar de las arraigadas nociones de extinción o desestructuración de las sociedades indígenas en el antiguo Tucumán colonial (las actuales provincias de Tucumán, Salta, Jujuy, Catamarca, La Rioja y Córdoba), ${ }^{11}$ pobladores rurales validaron en

10 Para Cuyo ver Michieli (2000) y su argumento de la "disolución" del indio en tanto "categoría jurídico social"u lealtadmoglo XIX y principios del XX istas,njusticiera, y por el otro que su lealtadmal" en el siglo XVII.

11 Esta tesis era sostenida hasta hace un par de décadas años por los principales referentes académicos del tema. Ver p.e. Ana María Lorandi, 1992, 1997. Un cambio de perspectiva al respecto empezó a producirse a fines de la década de 1990 por el impacto de la re-emergencia de identidades indígenas en la región (Isla, 2002). 
diversas ocasiones la posesión o propiedad de sus tierras esgrimiendo una condición indígena (Zubrzycki, Maffia y Pastorino, L. 2003; López, 2006; Fandos y Teruel, 2008; Rodríguez, 2010; Tell, 2010). La relación entre conflictos de tierras de pueblos de indios coloniales con los levantamientos montoneros o en general con las largas guerras civiles desde la década de 1820 hasta la de 1870 ha sido sugerida como tema de agenda, pero muy poco se ha avanzado en tal sentido. ${ }^{12}$ Los trabajos de Gustavo Paz sobre la insurrección de la década de 1870 y las luchas por el acceso a la tierra de los campesinos de la Puna de Jujuy constituyen una excepción (Paz, 1991, 2008, 2009 2005). Paz verificó la existencia de una historia política mayor por detrás de los levantamientos puneños que incluye, al igual que en Guanacache, una tradición de peticiones al gobierno ocasionalmente presentadas por funcionarios de gobierno locales o distritales. En Guanacache, sin embargo, parece haber existido una relación más directa de las demandas indígenas con el contexto político regional y nacional. Estas se articularon de un modo complejo pero decisivo con las guerras civiles entre federales y unitarios o liberales desde la década de 1820 , al punto de que, a pesar de su proximidad con las capitales cuyanas, las comunidades del área mantuvieron una relativa autonomía respecto de las élites provinciales que no lograron establecer su dominio en el área sino hasta fines de la década de $1870 .^{13}$

Pese a que se asume que los huarpes se extinguieron

12 Paz (2008), en su introducción a un reciente dossier temático alertaba de que "En los próximos años la investigación sobre los pueblos de indios del Tucumán debería abandonar su exclusividad colonial para tomar una perspectiva de más largo plazo, entre los siglos XVII y XX”. Y analizando la intensa conflictividad en torno del usufructo y la propiedad de la tierra en los Llanos de La Rioja entre los siglos XVIII y principios del XIX, Judith Farberman y Roxana Boixadós plantean que "El fenómeno de las montoneras del siglo XIX tiene indudable relación con esta conflictividad de larga data y todavía por conocerse" (Boixadós y Farberman, 2009, p. 81)."

13 Otra aparente diferencia con las demandas indígenas en la puna es que en Guanacache no se reclamaba solo el fin del arriendo sino el reconocimiento de la propiedad comunal de sus tierras invocando una historia reduccional. hacia el siglo XVII existen numerosos datos de la presencia indígena en el centro de Cuyo (considerada el área huarpe original) con bastante posterioridad. ${ }^{14}$ Hacia 1748 , retomando una política de larga data, la Junta de Poblaciones de Chile promovió la reducción a pueblo de indios de Corocorto, Jáchal, Valle Fértil y Las Lagunas (Verdaguer, 1931; Ardissone y Grondona, 1957; Michieli, 2004). Como ocurrió en diversos países de América, las reformas liberales del proceso independentista tendieron a socavar los derechos corporativos de tierras indígenas del período colonial, dando nuevo impulso a usurpaciones y privatizaciones. ${ }^{15}$

Desde la década de 1820 y a lo largo del siglo, sin embargo, la condición reduccional y el estatus indígena fue utilizada en Guanacache para defender judicialmente derechos a la tierra. Funcionarios locales nombrados por el incipiente gobierno provincial de Mendoza demandaron el reconocimiento de la propiedad colectiva indígena y lograron la restitución del cargo colonial de Protector de Indios. Este funcionario, Juan Escalante, inició en 1832 un proceso judicial para tal fin ${ }^{16}$ y en 1834 el fiscal de Estado dio por comprobada la posesión de aproximadamente un millón de hectáreas del norte de Mendoza por parte de los laguneros. ${ }^{17} \mathrm{El}$ juicio se realizó a lo largo de uno de los más cruentos períodos de la guerra civil en la región y los laguneros parecen haber sacado partido de los servicios militares que prestaron en ese contexto al bando federal. ${ }^{18}$

14 La matrícula de 1777 del Corregimiento de Mendoza, correspondiente a las tres provincias de Cuyo, censó 4.168 indios sobre un total de 23.411, sin incluir la población alejada de centros urbanos. El censo de $1812 \mathrm{del}$ primer período independiente contó 9.261 indios sobre un total de 43.204 individuos. Ninguno de estos censos, sin embargo, distinguen específicamente la población del área de las lagunas de Guanacache considerada indígena y es muy probable que sus habitantes no hayan sido censados (Torre Revello, 1939, pp. 77-84).

15 Escolar, 2013, 2015. Para el caso de Tucumán, ver López, 2006).

16 AHM, carp. 574, doc. 8, carp. 575 bis, doc. 17, fols. 13-14; Acevedo, 1979, pp. 142-43.

17 AHM, carp. 575 bis, doc. 17. fols. 15,16.

18 AHM, carp. 575 bis, doc. 17. fols. 13 y 23. En las conclusiones de la información recabada a los testigos sobre los derechos de tierras de los laguneros, Escalante había aludido implícitamente a la difícil situación política reinante como causa de la presión sobre las tierras de 
El 12 de marzo de 1838, el gobernador expidió un decreto por el cual se dispuso que "considerando la insinuación en que se hallan los naturales de Las Lagunas por no reconocer propiedad en los campos que poseen" y "por poderosas razones que ellos mismos a presencia del Subdelegado y de su párroco han impuesto" las tierras quedaban a su beneficio y no se admitían nuevos denuncios de particulares. Domingo Villegas, quien como juez había solicitado el nombramiento del protector a fines de la década de 1820, como subdelegado solicitó nuevamente en 1845 la designación de una "persona" y "ciudadano" que defienda los derechos de los laguneros "como se ha acostumbrado y los anteriores a V.E. aún desde los tiempos del Gobierno Español" aduciendo su cumplimiento fiel de las leyes y el culto católico y sobre todo su participación constante en "sostener la santa causa de la Federación con sus pequeñas fortunas y sus brazos". ${ }^{19}$

Es importante notar el protagonismo en estos conflictos de líderes locales como Villegas que formaban parte de la incipiente burocracia gubernativa de la provincia y al mismo tiempo protagonizaban el reclamo de los derechos de sus comunidades, asumiéndose como indígenas. Estos líderes-funcionarios laguneros parecen haber tenido un estatus particular en la incipiente formación estatal y el sistema de cargos públicos y es posible que los jueces laguneros hayan tenido las atribuciones de los "jueces subdelegados" que hacia 1820 fueron nombrados en cada villa de la provincia de Mendoza y que reunían la autoridad de policía, justicia y en algunos casos militar (Sanjurjo, 2004; Bransboin, 2015). En los documentos encontramos términos como "Juez de esta Reducción", "Juez de la Reducción del Rosario" o Asunción, ${ }^{20}$ o simplemente "Jueces Laguneros". ${ }^{21}$

\section{A partir de 1830 se creó la Comandancia Militar}

los laguneros, y sobre su propia persona como defensor. En su respuesta a las objeciones planteadas por el fiscal agregó que "solo ligeramente dio razones de política a favor de las pretensiones de los laguneros".

19 AHM, carp. 24, doc. 251.

20 AHM, carp. 574, doc. 8. Maza, 1980: 42, 109.

21 AHM carp. 575 bis, doc. 17; "Decreto Gubernativo, sobre los animales desconocidos del territorio de las Lagunas, y reglamentando el modo de recoger, seńalar y marcar”, en Ahumada (1860, pp. 68-70). y Subdelegacía de Las Lagunas y los jueces fueron reemplazados nuevamente por el cargo de subdelegado. Como veremos y ha sido notado para otras jurisdicciones de la provincia, en Las Lagunas estos subdelegados tuvieron bastante autonomía al punto que mediaban con el Estado intereses locales e incluso movilizaban reclamos de sus vecinos (Sanjurjo, 2004, pp. 287-88). Probablemente dependían también de la legitimidad otorgada por sus comunidades y los propios gobiernos se basaban también en ella para designarlos, al menos hasta la rebelión del Chacho Peñaloza. Este parece haber sido el caso de Villegas, quien mantuvo funciones de autoridad estatal local y al mismo tiempo demandas contra el propio gobierno a lo largo de 40 ańos, para finalmente ser sumariado y destituido en 1862 por una supuesta colaboración con la insurrección. ${ }^{22}$

La categoría "jueces laguneros", una particularidad local, probablemente ocupó el espacio dejado por la desaparición del cargo de cacique (que en Cuyo existió hasta principios del siglo XIX) y de los alcaldes de los pueblos de indios, que persistieron al menos hasta 1789 (Vignati, 1953). Esto coincidiría con lo ocurrido durante los inicios del proceso independentista en otros contextos latinoamericanos, donde los indígenas accedieron a cargos civiles como una de las principales vías de participación política y desde allí mediaron entre los intereses locales, los terratenientes y el Estado (Díaz, Ruz y Galdames, 2011; Chiaramonti, 2005; Godoy, Orellana y Contreras Cruces, 2007).

El nombramiento de estas autoridades por parte del gobierno de Mendoza desde mediados de la década de 1820 tenía el objetivo de ejercer alguna forma de control en un área indominable. Pero desde el principio de su actuación estas mismas autoridades motorizaron demandas por tierras de comunidad avasalladas por terratenientes de la primera plana del poder político, tanto unitarios como federales. Casi podría sugerirse que a partir de esta doble representación política los jueces y subdelegados laguneros no solo negociaron su relación con el incipiente estado mendocino, sino más bien demandaban y construían una estatalidad con bases y agendas diferentes, orientadas al menos en parte a la protección

22 AHM, Judicial Criminal, época independiente, 2 A, doc. 27. 
de los campesinos y antiguas castas y la preservación de tierras y autonomías indígenas. Las propias demandas de instituciones de justicia en un período de relativo vacío jurídico, la ejecución de funciones de gobierno local en un tiempo de endémica ingobernabilidad y guerra civil, la preservación de un archivo local, la negociación y aporte de tropas a los ejércitos libertadores y luego a los federales, evidencian una voluntad republicana no menor que sus contrapartes urbanas. Analizando las rebeliones realistas de Huanta, Perú a principios del período independentista, Cecilia Méndez (2005) demuestra que los planteos de los líderes indígenas y las prácticas de gobierno desarrolladas tenían un contenido más republicano y democrático con relación a los indígenas que aquellos declarados por los independentistas. Su hipótesis principal es de hecho muy semejante a la que manejamos para Guanacache: que los campesinos indígenas movilizados y sus líderes, incluso a través de la guerra, más que rebelarse "contra el Estado" querían y de hecho contribuyeron a constituir el Estado en un contexto de vacío de autoridad gubernamental. Los campesinos andinos que cumplían funciones delegadas de gobierno ante la incapacidad de éste de ejercer control, más que representar al Estado eran de hecho el estado. Sin embargo, esa institucionalidad en Guanacache a principios del siglo XIX estaba fuertemente asociada a una condición indígena, la cual era tanto la base del sistema de autoridad local como de la legitimidad de la ocupación de la tierra.

Las acciones de Santos Guayama y la larga insurrección de Las Lagunas se producen poco tiempo después de la derrota del ejército federal por parte del ejército de Buenos Aires en la batalla de Pavón y la asunción de Bartolomé Mitre en la presidencia de la Nación entre 1862 y 1868 . Conviene repasar brevemente la situación de Guanacache y los eventos ocurridos en los albores de la rebelión del Chacho para entender el desarrollo posterior de los hechos. Luego de la batalla de Pavón en 1861 el ejército nacional -en rigor el de la Buenos Aires liberal-invadió las provincias federales. Al poco tiempo comenzaron a producirse conatos de rebelión, siendo el principal el que se desarrolló bajo el liderazgo del Chacho. El levantamiento, que tuvo dos etapas mediadas por un acuerdo, llegó a abarcar todo Cuyo, parte de Córdoba, Salta y Catamarca, y fue reprimido cruel- mente bajo la dirección del nombrado gobernador de San Juan y director de la guerra contra el Chacho, Domingo Faustino Sarmiento. El Chacho fue asesinado al entregarse a una patrulla enviada por este último.

El primer incidente que anunció la rebelión fue la reunión de una montonera en Las Lagunas por parte del cabecilla Gerónimo Agüero. A instancias de Luis Molina, gobernador de Mendoza designado también a instancias del ejército de Buenos Aires acantonado en la provincia, el subdelegado Domingo Villegas y el hacendado Francisco Alvino fueron procesados bajo acusación de estar de acuerdo con Agüero para promover el levantamiento en Las Lagunas en apoyo al Chacho. ${ }^{23}$ Luis Molina preparó una expedición militar para "traer a cuanto vecino haya por allí para que pueblen en el sur más bien”. ${ }^{24}$ Sarmiento, que había enviado ya dos expediciones, le escribió advirtiendole que Las Lagunas,

\section{[...] sobre todo las de Mendoza están muy} pobladas de gente, con más de diez mil cabezas de ganado. Créese que la montonera ha sido de más de 200 hombres, lo que da un total de población considerable. La violencia necesaria para arrancar gentes de los lugares en que han nacido traerá una sublevación, fundada en sentimientos legítimos, aunque extraviados, y acaso Peñaloza adquirirá una centena de desesperados que le ayuden.

El sanjuanino fue como siempre premonitorio: "esa población, atacada por sus fuerzas, dará por resultado engrosar las filas del Chacho". ${ }^{25}$ El 20 de mayo,

23 AHM, Judicial Criminal época independiente, $2 \mathrm{~A}$, doc. 27. Interrogado en el sumario Villegas, entonces de 68 ańos, muestra un vínculo muy directo con el gobernador y mantiene un lenguaje republicano y legalista. Declara que "cuando llegó al pueblo [la ciudad de Mendoza]" el gobernador le preguntó "si se había estado carteando con Gerónimo Agüero", a lo cual respondió afirmativamente. En la indagatoria dijo que Agüero lo había invitado imperativamente dos veces por carta para levantar a la gente de Lagunas del Rosario, a lo cual le habría respondido que "no reconocía ninguna autoridad en él y que no pertenecía a esta provincia”.

24 Archivo de Domingo Faustino Sarmiento (en adelante AS), armario I, doc. 5016.

25 AS, carp. 35, doc. 3805. 
a escasos días de que Villegas fuera traído y procesado en la ciudad, Molina personalmente invadió Las Lagunas con 250 hombres entre fuerzas de Buenos Aires y provinciales. ${ }^{26}$ Lino Almandoz, comandante de Armas de Mendoza, escribió más tarde a Mitre sobre la invasión de Molina describiendo prácticas represivas como las denunciadas por los líderes montoneros, desde el propio Chacho hasta Felipe Varela. Según cuenta Almandoz, Molina no trasladó a toda la población pero "les quitó a las familias los hijos de ambos sexos, los que se hallan repartidos en diferentes puntos" ${ }^{27}$. De los hombres que se presentaron al llamado que les hicieron los comandantes Flores y Pais, fusilaron cuatro, sin formación de causa. Uno de ellos, Gregorio Morces, "estaba arreglado por Don Marcelino Quiroga" quien fue con las fuerzas de Buenos Aires. Otro, Juan José Ochoa, "manco y trabajador”, había acompañado al Chacho cuando acudió a San Juan tras el asesinato del gobernador Benavides por los liberales locales ${ }^{28}$ y no había tomado parte en la nueva campaña del Chacho. Sostenía a la madre y una hermana viuda con seis hijos, y el mayor Flores secuestró además al único hijo varón. ${ }^{29}$ Molina hizo arriar el ganado de los laguneros que engrosaron los puestos de su estancia y tomó "seis chinitas para regalar". El propio Almandoz se apropió de Domingo Agüero, de 13 ańos, para su servicio. Tres días después respondía a Sarmiento:

Todos los gobiernos antecesores al mío han tenido la idea de desalojar esos parajes por que han comprendido, sin duda, el beneficio que resultaría al país. Esos habitantes jamás han prestado servicio alguno a la Provincia: siempre han estado dispuestos a hacer armas contra las autoridades y a favorecer entre sus

26 AS, armario I, doc. 5016.

27 Carta del coronel Lino Almandoz al Presidente de la Nación Bartolomé Mitre, Rosario 30 de diciembre de 1862. Archivo del General Mitre, Tomo XII: 179. Lo mismo se practicaba con prisioneros indígenas del sur de Mendoza y la región Patagónica desde la época colonial a la Campaña del Desierto entre 1878 y 1885, al igual que el traslado forzoso de familias laguneras a las guarniciones de la frontera indígena del sur de Mendoza, documentadas desde principios del siglo XVIII.

28 Hecho que inició la cadena de asesinatos de gobernadores de San Juan que a su vez desembocó en el enfrentamiento de federales y liberales en la batalla de Pavón.

29 Op. cit., 179. madrigueras a los criminales de La Rioja, San Luis y San Juan que escapan de la justicia. Yo he sido el protector que han tenido; pues siempre me opuse y me empeñé a fin de que tales proyectos no se realicen, esperando que algún día podrían moralizarse y ser útiles al país; pero los últimos acontecimientos ocurridos allí alejaron completamente mi esperanza y me prueban que esos malvados son incorregibles.

Sarmiento dudaba de la real culpabilidad de los tomados o asesinados. En carta a Molina contaba que el cabecilla de unos bandidos que sus tropas habían apresado (y en su mayoría fusilado), Tomás Núñez, era "un paisano formal, al decir de todos honrado, dueño de una buena fortuna y padre de una numerosa familia”. Más tarde publicaría (contradiciendo su conocida criminalización de la montonera) que "de los prisioneros tomados, solo quince en más de ciento no tuvieron quién solicitase su libertad y los acreditase honrados, lo que probaba que eran todos gente conocida y de buena familia" (Sarmiento, 1947 [1866], p. 109).

Estos hechos inauguraron un ciclo represivo de más de 15 años en que Las Lagunas fueron foco permanente de rebelión y el área pasó a ser considerada prácticamente un frente militar. También, los sucesos parecen marcar el fin del reconocimiento oficial de las autoridades locales. El subdelegado Villegas fue sacado de Las Lagunas y procesado días antes de la invasión. No volvió a ejercer ese cargo, la más alta representación departamental, pero luego de 40 años de ejercicio del gobierno local, continuó como comisario del paraje de Asunción. ${ }^{30}$ Contrastando con la negociada pero relativamente efectiva articulación institucional que representaban las autoridades laguneras previas, a partir de allí será muy difícil someter a los pobladores al control estatal mendocino. El cargo de subdelegado departamental ya no sería ocupado por un lagunero pero si los demás de la burocracia local. El nuevo subdelegado, ahora si personero directo del gobierno provincial, recorrió los distintos parajes "para arreglar los empleados". ${ }^{31}$ Esta decisión y las reuniones con vecinos en cada

30 AHM, carp. 574, doc. 98.

31 Op. cit. 
paraje sugiere una negociación más que una imposición de cargos en las segundas líneas. Villamil reorganizó la administración local nombrando una planta mayor que la previemante existente, de doce empleados en cada uno de los tres distritos, conformada por un comisario, un teniente de comisario, dos ayudantes del comisario, un alcalde del primer cuartel, con su teniente y dos ayudantes, y un alcalde del segundo cuartel, a su vez con un teniente y dos ayudantes. Pero esta designación masiva de empleos públicos no bastaba para garantizar la disciplina política de los laguneros. El subdelegado se quejaba al gobierno de que pese a haber designado a los empleados, no existían soldados ni guardia nacional ni policía activa en el departamento encontrándose "aislado" porque "la gente lagunera no reconoce cuerpo". Agregaba que en realidad preferían dedicarse a la cosecha del trigo antes que llenar los cargos públicos. ${ }^{32}$

Pese al triunfo de los liberales y su inicial desconocimiento de las autoridades locales, eran evidentes las limitaciones del control político en el área. La mayoría de los cargos quedaron en manos de los laguneros, incluso de quienes como Villegas (designado comisario de Asunción) habían sido sumariados por su posible apoyo al Chacho. La lealtad de estos funcionarios, como la de los hacendados locales era por lo menos dudosa y en cambio, evidente su permeabilidad con los "bandidos". Víctor y Francisco Alvino, los principales hacendados del departamento, las autoridades y los mismos soldados, eran acusados de proteger a los bandoleros o montoneros. Ya en plena actuación de Guayama, el subdelegado José Ibarzábal se quejaba en 1867 de que...

Se sabe que Don Pancho Alvino ha abrigado algunos bandidos y su hermano Don Víctor Alvino también [pide al gobernador] se sirva mandarme militares armados para ya hacer pesquisa de dichos individuos porque los militares que tengo no tengo confianza en ellos, porque son del mismo Departamento, aunque lleguen a verlos no me los han de presentar, antes bien les han de dar escape. ${ }^{33}$

32 Op. cit.

33 AHM, carp. 574 bis, doc. 9.
En esta misma línea, el intendente general de Policía de San Juan comunicaba en 1871 que "el Comisario o autoridad de Mendoza en Las Lagunas recibía las cabalgaduras robadas por Guayama a pastar en el territorio provincial y había guardado también allí varios robos, y que su propio hijo había estado con Guayama en una reciente refriega, dándole el aviso que era atacado por el Mayor Carrizo" (Siri, 1947, p. 83).

\section{La insurrección de Guanacache}

Como hemos visto, en Las Lagunas están muy frescos los recuerdos de Guayama asociados a una imagen de autonomía y protección política. Esto fue, según contaba el anciano Sixto Jofré, cuando los huarpes hicieron "pata ancha" para defender la tierra. En su monografía sobre Guanacache de 1922, el famoso antropólogo suizo Alfred Métraux narró la persistente impresión que el caudillo había dejado, instalándose como primer tópico de las narrativas históricas locales. A tal punto que se quejó en el texto de que en lugar de brindarle datos sobre tradiciones indígenas, su primer informante...

[...] mostrose inagotable acerca del tema de los antiguos caudillos gauchos. Me habló largamente del célebre jefe bandolero Santos Guayama quien con sus secuaces se refugió en la región de Huanacache, y durante largos ańos tuvo en jaque a las autoridades constituidas de la provincia. $\mathrm{Mi}$ interlocutor me hablaba con simpatía y parecía estar orgulloso del encuentro que tuvo en su infancia con Santos Guayama. Me describió complacido, su vestimenta, su gorro rojo y sus aperos de plata. También me enteré por él como Santos Guayama habiendo sido invitado a San Juan, fue víctima de una emboscada, siendo fusilado sin juicio previo (Métraux, 1937, p. 5).

El patriarca Vicente González contaba de las enormes fogatas que hacían los montoneros para convocarse, mientras que la familia Agüero me mostró la "cancha de los indios", donde los montoneros entrenaban a sus caballos en el barro para desarrollar su musculatura y enseñarles destrezas como galopar aún boleados. Juan Nylo Reinoso, por su parte, 
describió la guerra a muerte con los "sanjuaninos" tal como fue contada por sus mayores donde a falta de armas tensaban "torzales" de cuero entre dos caballos y a pleno galope arremetían contra las patrullas enemigas, arrastrándolas o cercenando sus cabezas.

El historiador sanjuanino Horacio Videla relataba que hacia la década 1970 conoció un peón de apellido Guayama con...

[...] mirada acerada y sugerente; voz grave que envidiaría el barítono o bajo de cualquier teatro vocacional; porte recatado, circunspecto. El encuentro nos hizo advertir que algún rasgo de nobleza o de generosidad en Guayama [...] ganaba el sentimiento de todos a favor del temido gaucho, autor de asaltos y saqueos. Sentados en rueda junto a las brasas del fogón, después de la jornada de pago, escuchamos a ese hombrecito referir a los contertulios con voz queda y en vena de confidencias, cómo Santos Guayama despojaba a los que las cosas sobraban para ayudar a los pobres, como protegía mujeres desvalidas, viudas y huérfanos. Y una lumbre de admiración se encendía en la pupila de los peoncitos jóvenes, como en el semblante de los viejos criollos (Videla, 1989, p. 300).

El anciano Ceferino Nievas recordaba que según le transmitieron su padre y su abuelo Guayama se trasladaba con ochenta hombres parando en los "puestos" campesinos donde previo pedido carneaba una vaca para dar de comer a sus soldados y requería un "personal" (un miembro de la familia, peón o agregado) para su pequeño ejército. Era un "rico", un "hombre hacendado" que vestía con elegancia criolla y se conducía con respeto. Muchos afirman que repartía a los pobres del botín que obtenía de los asaltos, pero también existen versiones que acentúan su crueldad, rememorando asesinatos y torturas cometidos por su orden. En general, éstos son presentados como castigo a traidores o espías, mostrando por un lado su carácter justiciero y por el otro que la lealtad a su causa, o por lo menos el silencio sobre sus movimientos, eran exigidos con sangre.
La asociación de Guayama con la defensa del territorio tiene un cierto correlato con la geografía de la guerra y el mapa de las tierras reclamadas por los laguneros (véase Figura 1). Partes militares y policiales de San Juan, San Luis, Mendoza y La Rioja dan cuenta de la dinámica de interminables persecuciones a Guayama que giraban en torno o atravesaban el área lagunera. Luego de meses de ostracismo, el caudillo se mostraba en alguna pequeña localidad de la travesía cercana a la frontera entre San Luis, Mendoza, La Rioja y San Juan. Eventualmente, seguían asaltos el trafico carretero en la ruta que por el norte de Las Lagunas vinculaba Cuyo con Córdoba y el Litoral. Seguía un ataque resonante a algún pueblo. Luego, la infructuosa persecución por parte de tropas enviadas desde algunas de las mencionadas provincias (guardias nacionales, policías o municipales, y en algunas ocasiones del ejército de línea). Estas persecuciones alcanzaban y mataban a veces a los rezagados, pero el grueso de los montoneros se dispersaba y huía por los extensos medanales y sierras que median entre San Juan y los Llanos de La Rioja, como Pie de Palo, Gigantillo, la Sierra de las Minas o Guayaguás.

Guanacache y su entorno, como señalara Sarmiento y muchos contemporáneos, eran un asilo para montoneros de Cuyo, La Rioja y Córdoba. Desde la rebelión del Chacho se convirtieron en el principal refugio de los montoneros dispersos aunque siempre lo fue de bandidos, salteadores y perseguidos políticos tanto por sus características ambientales como sociales y políticas. Se trataba de un desierto intrincado, atravesado por un arco de lagunas, pantanos y bosques espinosos. Al mismo tiempo existían (en Las Lagunas del Rosario, San Miguel, en el noreste de Las Lagunas cerca del límite con San Luis o a lo largo del río Desaguadero) zonas de difícil acceso pero con buenos pastos donde los montoneros podían reponer a las caballadas o esconder el ganado robado. Cuando había sequía, las tropas no podían alcanzar a los montoneros porque sus caballos no podían abrevar, y ellos al igual que los indígenas del sur utilizaban esta circunstancia en su estrategia. ${ }^{34}$

34 En 1865 un ataque de los indios de la Pampa a La Paz, en el río Desaguadero coincidió con una "horrible seca" que impidió la persecución porque las cabalgaduras del ejército no podían abrevar. AHM carp. 698, doc. 60 . 
Cuando no la había, el ingreso a través de ríos y pantanos solo podía efectuarse con la anuencia de los laguneros que "Cruzan a caballo de San Juan a Mendoza y visceversa toda esa extensión de agua por ciertos puntos que solo ellos conocen como vadeables" (Igarzábal, 1873, p. 76), pero esta complicidad era difícil de obtener y se pagaba con la vida. En 1868 la Receptoría de Armas de Mendoza solicitaba un suplemento económico para que Jesús Cortés pudiera establecerse en la ciudad a los fines de no ser asesinado, debido a que

\section{[...] desde el año sesenta y uno sirve de va-} queano en las distintas expediciones que se han hecho a Las Lagunas, a la cual se agrega que siempre ha prestado sus servicios a la buena causa, combatiendo a los malhechores que infestan esos lugares, los cuales lo han perseguido y saqueado, dejándolo en la miseria, teniendo que andar fujitivo de su casa por abrigar serios y fundados temores de ser asesinado. ${ }^{35}$

Una vez escondidos en algún punto de Las Lagunas y repuestas sus cabalgaduras, los perseguidos tenían buenas chances de fugar en muy diversas direcciones: Los territorios indígenas libres del sur y sureste denominado Tierra Adentro (el territorio ranquel, en el sur de las provincias de Córdoba y San Luis y la actual provincia de La Pampa); hacia alguna de las tres provincias de Cuyo o La Rioja; o hacia Chile. Estas opciones ofrecían escenarios políticamente muy diversos en los que obtener protección, y los montoneros explotaban los antagonismos que inexorablemente existían entre algunas jurisdicciones. Según los partes militares de la rebelión del Chacho, Fructuoso Ontiveros y Juan Gregorio Puebla "asilados en los Llanos de La Rioja con un grupo de cerca de cien forajidos" entraron a Las Lagunas "persiguiendo al Subdelegado o Comisario de allí, cometiendo saqueos y robos a los transeúntes". ${ }^{36}$ Una vez en Las Lagunas estos procuraban "pasarse a Tierra Adentro por la costa de Las Lagunas o Desaguadero, ya sea por esa o esta provincia" o "ver si de ahí pueden pasar a Chile o a Tierra Adentro". ${ }^{37} \mathrm{La}$

35 AHM, carp. 307, doc. 20.

36 AHM, carp. 698, doc. 12.

37 AHM, carp. 698, docs. 13 y 15. Esta relación fue ha- costa del Desaguadero, entre las provincias de San Luis y Mendoza, era una importante área de pastoreo y uno de los puntos más desguarnecidos de la frontera con los indígenas del área pampeana y patagónica. ${ }^{38}$

No puede comprobarse aún que el propio Guayama se haya refugiado también con los ranqueles, pehuenches $\mathrm{u}$ otros grupos indígenas de la frontera sur. Pero sí está claro que sus desplazamientos se combinaban a menudo con ataques de indígenas del sur, o de montoneros y bandidos refugiados en su territorio, que distraían las tropas. Guayama se aproximaba a la frontera sur y luego tomaba hacia el norte por el área adyacente a Las Lagunas, explotando la preocupación de los perseguidores por una combinación con ataques desde el sur y obligando a los comandantes a dividir fuerzas.

Uno de los principales atributos de Las Lagunas como refugio era el hecho de encontrarse en la encrucijada fronteriza entre tres provincias cuyanas y La Rioja. Los dispersos podían eludir la persecución simplemente pasándose de una a otra provincia, explotando la falta de competencia jurisdiccional de las partidas y las eventuales diferencias políticas entre sus gobiernos o los propios mandos militares y policiales. En abril de 1865, con la formación de una montonera dirigida por Berna Carrizo en Los Llanos, el gobierno de San Luis solicitó al de Mendoza un acuerdo para permitir que milicias de San Luis pudieran penetrar en Las Lagunas por el territorio de Mendoza cuando perseguían montoneros, debido a que "en la persecución que hacen a los

bitual para las montoneras cuyanas y riojanas al menos desde la rebelión del Chacho Peńaloza en 1862. Este tema ha sido tratado por Marcela Tamagnini y Graciana Pérez Zavala (Tamagnini, 2007).

38 Las autoridades puntanas trataban de que se colocase un fuerte en la línea divisoria de ambas provincias "Estando por consiguiente a merced de la rapacidad del salvaje de las Pampas, pues quedan a una inmensa distancia de los fuertes establecidos tanto en esa Provincia como en esta”. AHM, carp. 698, doc. 16. El riojano Ozán a quien "los forajidos llaman Comandante, [y] tiene su residencia en los Llanos, casi en la línea que separa esta provincia con la de La Rioja, y siempre ha sido puntero aún en tiempo de paz" se escapó con su familia a Huilasta al oeste del Desaguadero". AHM, carp. 698, Documento 61. 
ladrones, tocan con el inconveniente de que éstos se trasladan a la otra provincia, esterilizándose así la persecución". ${ }^{39}$ Otra comunicación del gobierno de San Luis al de Mendoza planteaba la necesidad de una entrada simultánea a Las Lagunas de tropas de las tres provincias.

\section{[...] Las Lagunas y sus adyacencias donde} ahora, como siempre, son la guarida y punto de cita que se dan los bandoleros de las Provincias de Cuyo y de La Rioja y aún de la de Córdoba. Una entrada en combinación de fuerza de las tres Provincias producirá buenos resultados, es seguro porque serán disueltas esas bandas de ladrones que se están formando, y porque verán que ya se pierden permanecer en esos puntos con la seguridad y confianza como lo han hecho en años anteriores. ${ }^{40}$

En estas entradas era crucial contar con algún apoyo de los pobladores para aprovisionarse, señalar los caminos, el estado del terreno y la disponibilidad de agua en cada época del año. Este "conocimiento local" involucraba estrategias de comunicación, rastreo e inteligencia, y se volcaba más bien en ayuda de los fugitivos. Uno de ellos eran los avisos mediante señales de humo que se ven a $30 \mathrm{~km}$, que se hacían previo acuerdo transmitiéndose de puesto en puesto (Siri, 1947)..$^{41}$ También usaban técnicas de rastreo y contrarrastreo, en la cual eran reputados como expertos. ${ }^{42}$ Según cuentan los laguneros sus ancestros ayudaban a borrar las huellas de Guayama con diversas técnicas, por ejemplo echando una majada de cabras por detrás de los montoneros en fuga.

39 AHM, carp. 699, doc. 3.

40 AHM, carp. 699, doc. 21.

41 Esta técnica, que en la noche se realiza con señales de fuego entre puntos altos, está vigente hasta ahora en la campaña cuyana, como pude apreciar entre cazadores furtivos en el área cordillerana de San Juan y en recogidas o campeadas de ganado vacuno en Las Lagunas.

42 Es célebre la caracterización de Sarmiento sobre el rastreo cuyano en Facundo (1963), que da lugar a un capítulo llamado precisamente "El rastreador", que combinados con "El baqueano" y "El gaucho malo" son utilizados para explicar el sustrato cultural del gaucho en general y del caudillo Facundo Quiroga en particular.
La guerra ponía en juego también redes sociales y políticas entre puesteros, arrieros, autoridades locales y las propias élites provinciales. Los documentos y la literatura de época sugieren que los montoneros y sus bases eran una masa informe de "fascinerosos" no solo sin proyecto político sino sin cualidades ni nombres propios, a excepción de sus caudillos. Sin embargo, a menudo se observa la importancia del conocimiento interpersonal para el desenvolvimiento de las operaciones y el carácter individualizado de la represión. Los asesinatos selectivos de la invasión del gobernador Luis Molina a Las Lagunas, donde incluso había individuos "arreglados" previamente por distintas personas para ser asesinados, son un ejemplo de esto. ${ }^{43}$ También el conocimiento pormenorizado que el gobernador y los fiscales tienen sobre referentes políticos o simples habitantes de Las Lagunas, como se observa en el sumario a Francisco Alvino y al subdelegado Villegas poco antes de inicio de la insurrección del Chacho. ${ }^{44} \mathrm{Y}$ finalmente, también las venganzas individualizadas de algunos montoneros. Como veremos más adelante un guarda de aduana es amenazado de muerte por un capitán de Guayama por haberle confiscado su caballo durante una pasada invasión a Las Lagunas.

Pese a la insistencia de la literatura regional no existen datos fiables (ni siquiera en partes militares y policiales) de que Guayama asesinara en sus asaltos a pobladores, arrieros de tropas o viajeros. Su blanco eventual eran los militares del ejército de línea, raramente los soldados de las Guardias Nacionales provinciales.

Es posible que esto se haya debido a que realmente el caudillo estaba interesado en mantener su legitimidad política y también porque todos estos actores eran potenciales reclutas. En la estrategia militar la captación de reclutas del otro bando cumplía un rol a veces más importante que el combate en sí mismo, especialmente luego de las levas para la guerra del Paraguay. Las montoneras se nutrieron en gran medida de desertores que con frecuencia también

43 Carta del coronel Lino Almandoz al Presidente de la Nación Bartolomé Mitre, op. cit.

44 AHM, Judicial Criminal época independiente, 2 A, doc. 27. 
eran reincorporados por sus antiguos jefes una vez recapturados. ${ }^{45}$

\section{El Estado montonero: deseo y decepción}

En 1868 luego de la derrota de Felipe Varela, Guayama y otros montoneros tomaron la ciudad de La Rioja, y Chilecito, y negociaron con el general Navarro enviado a reprimirlos un indulto a cambio de deponer las armas. Pero luego el acuerdo, que contaba con el aval del presidente de la Nación, fue desestimado por el gobierno quien envió en su persecucion al general Arredondo, antiguo azote de las montoneras desde la represión del Chacho. En una carta dirigida a Navarro, Guayama, Elizondo y otros jefes ofrecieron nuevamente rendirse a cambio del ansiado indulto quejándose de que el "Exmo. Gobierno Nacional" les había "atribuido el carácter y las tendencias de montoneros rebeldes contra las autoridades de la República y de la Provincia”.

Cuando abrigábamos la esperanza de gozar de una paz duradera en la Provincia de La Rioja, bajo los auspicios de un Gobierno prudente, previsor y moderado, de cuya política hábil y conciliadora podríamos esperar nosotros mismos un perdón generoso a nuestros pasados extravíos, para no pensar en adelante sino en llevar una vida de abnegación ejemplar, sujetos en todo a la ley y a las autoridades, se nos desvaneció completamente aquella halagadora esperanza al ver un General llamado a ser juzgado en la Capital de la República por un consejo de Guerra en virtud de un decreto superior, lanzarse de repente desde la ciudad de Córdoba sobre la desgraciada Rioja a atacar y derrocar sus autoridades legítimas [...] Entonces, Sr. General, empezó para nosotros la persecución y la amenaza, para el pueblo la intranquilidad y la alarma, y para la República toda el escán-

45 Ariel de La Fuente ofrece una muy buena descripción de la problemática. En 1869 casi la mitad de los guardias en los llanos riojanos al mando de Ricardo Vera, uno de los más fieros perseguidores de Guayama, eran de otras provincias para tratar de evitar la identificación o solidaridad de los perseguidores con los perseguidos (De la Fuente, 2010, p. 246). dalo y la indignación. Fue por eso también que creyendo hacer uso de un derecho legítimo y rendir un servicio a la causa pública y aún al gobierno mismo de la Nación, nos resolvimos a tomar las armas y venir a La Rioja a restaurar las libertades públicas, y a poner a nuestro país en aptitud de reparar sus males y reivindicar sus derechos [...] nunca habíamos pensado siquiera en provocar trastornos y revueltas políticas que se nos atribuyen con que hemos guardado y hecho respetar el orden en la ciudad de La Rioja durante nuestra permanencia en la plaza. ${ }^{46}$

En 1868 durante la presidencia de Sarmiento, una división del Ejército alcanzó a Guayama, que pudo escapar, pero su secretario, Zacarías Segura, fue tomado prisionero. ${ }^{47}$ A Segura se le incautaron algunas cartas escritas o recibidas por Santos Guayama, que Sarmiento publicó en un folleto destinado a demostrar la connivencia de éste con los hermanos Taboada, caudillos de Santiago del Estero aliados con Mitre. ${ }^{48}$ En un borrador de carta a Manuel Taboada,

46 En Arias (S.D.), mimeo. Los firmantes son: Sebastián Elizondo, Santos Fernández, Aurelio Zalazar, Santos Guayama, Olegario Vidal, Belisario Quiroga, Indalecio Nieto, Felipe Heredia.

47 Una amplia opinión tanto entre los sectores populares como de la alta sociedad de San Luis clamaba por su perdón y juzgamiento en el fuero civil, y hubo señoritas que ofrecieron casarse con él para que no fuera ajusticiado. El caso tuvo amplia repercusión nacional. Mitre y sus aliados, en dura oposición, aprovecharon el suceso (cuyo antecedente era el asesinato del Chacho Peñaloza, también bajo responsabilidad de Sarmiento) para interpelar a Sarmiento en el Senado y acusarlo por la aplicación del estado de sitio para el asesinato de enemigos políticos. Una de las principales causas del revuelo generado hasta en las máximas instancias políticas de la república fue que el joven Segura era blanco e instruido. Como el propio Sarmiento reconoció, en gran parte por esto se generaron los "acalorados debates del Congreso sobre si Segura era un caballero con ojos azules o un salteador" (Belin Sarmiento, 1902, p. 277).

48 Los alineamientos políticos de Guayama no son fáciles de determinar. Como vimos se insiste con que fue lugarteniente del Chacho Peńaloza durante la rebelión de 1862-63. En 1867 fue uno de los cabecillas de la "Revolución de los Colorados" en Mendoza y San Juan y luego siguió a Felipe Varela en su levantamiento al mando de mil hombres y se enfrenta al comandante del Ejército Nacional en el Noroeste, Manuel Taboada, go- 
caudillo mitrista de Santiago del Estero, el montonero apela a los términos del acuerdo. ${ }^{49}$

[...] después de la convulsión hecha por el Coronel Elizondo la cual dio por resultado la toma de La Rioja y que después vino la intervención del Señor General Navarro como Comisionado del Gobierno Nacional a quien nos sometimos a él por medio de un tratado de garantía para todos los jefes y oficiales de la división por el cual se nos azenaba (SIC) que todos quedábamos en ejercicio de nuestros empleos como jefes de nuestros respectivos departamentos y que no seríamos molestados en lo sucesivo y quedábamos todos sometidos al gobierno obedeciendo sus órdenes que se nos impartieran por el gobierno de la provincia y pusimos en manos del gobierno las armas que pertenecían a la provincia y todos nos retiramos bajo de tales garantías al goce de nuestros hogares solo esperando órdenes para desempeñar y ayudarlo y sostenerlo en todas sus partes como empleados de la provincia. En cumplimiento del tratado nos retiramos y el resultado fue que luego nos vino la destitución de nuestros empleos dejando las plazas en acefalia y sin autoridades locales y luego más tarde le vino primeramente la prisión al Coronel Salazar, al Coronel Chumbita, al Sr. Bravo y ame-

bernador mitrista de Santiago del Estero. Entre 1868 y 1871 operó fuertemente en la política sanjuanina. En un caso de crisis institucional, Guayama acude en favor del gobernador Zavalla y se alía con Taboada, jefe de la División del Norte del Ejército Nacional, en ese momento enfrentado con el presidente Domingo F. Sarmiento. En la revolución mitrista de 1874 dará su apoyo a su acérrimo enemigo, el general Arredondo, que tomó Mendoza durante cinco meses, siendo derrotado por Julio Argentino Roca en la Batalla de Santa Rosa. Luego, hará campaña presidencial por Carlos Tejedor y en 1878 por el candidato roquista a gobernador de San Juan, Agustín Gómez, quien al año siguiente ordenará su asesinato. El enemigo con el cual nunca parece haber pactado y que acicateó su persecución con encono hasta el final de su presidencia, fue Domingo Faustino Sarmiento.

49 Santos a Guayama a Manuel Taboada, 22 de febrero de 1869 (Sarmiento, 1869, pp. 32-33). Las partes en cursivas corresponden al original. nazadas las personas del Coronel Elizondo, Flores, el Comandante Nieto y el que suscribe ordenando persecución de muerte contra nosotros. Teniendo en vista la persecución que se ordena contra mi persona y los demás y hostilizado me he visto obligado a alarmarme y ponerme a la defensa para de este modo pedir el cumplimiento de esas garantías al gobierno de la Provincia como que está ordenado por la intervención de cumplirla en todas sus partes. [...] En orden al estado de la política tenga a bien comunicarme y ordenar todo cuanto Vtra. estime conveniente contando con mi amistad y decisión así a Vtra. y como soldado no tengo embarazo en ofrecerle $\mathrm{mi}$ servicio con toda lealtad.

En esta pieza podemos observar algunas características centrales del discurso de Guayama. La apelación a una legitimidad y legalidad supuestamente oficial y las demandas de "empleo" en la burocracia estatal como autoridades locales legítimas. ${ }^{50}$ Recordemos que los jueces laguneros presentaban la misma dualidad cuando pleiteaban contra el propio estado del cual eran funcionarios, o negociaban demandas por apoyo militar en medio de las conflagraciones armadas partidarias. Guayama reclama ser él mismo un representante del gobierno nacional, aun cuando el gobierno lo persiguió durante años como bandido común. En cartas de junio y agosto de 1868 encontramos las mismas ideas: Guayama consideraba "calumnioso" el mote de "rebeldes y en contra del gobierno nacional" dirigido a sus tropas, y manifestaba que "él no es montonero, pues está al servicio de [el gobierno de] la nación” (De la Fuente, 2010, p. 112).

Adoptando un lenguaje burocrático, el discurso gubernista de Guayama parece ir en aumento proporcional a la criminalización y barbarización de su

50 Méndez (2007) desarrolla el caso de los rebeldes de Huanta, en Perú, donde los caudillos realistas plebeyos que representan a los campesinos/indios, tienen como una de sus principales aspiraciones incorporarse con cargos en el Estado, basando su legitimidad en la guerra e invocando la representación genérica del gobierno a nivel local. 
figura. Esta dualidad fue registrada en una interesante crónica de la época sobre el resonante asalto de Guayama a la aduana de Uspallata en los primeros días de abril de 1872. El resguardo de Uspallata, en las estribaciones de los Andes, era el último punto de control fronterizo y aduana Argentina en la ruta interoceánica entre Buenos aires y Santiago de Chile-Valparaíso, eje de un importante tráfico ganadero y de cargas que constituía el motor de la economía cuyana. El diario El Constitucional de Mendoza reprodujo una carta enviado por el guarda de la aduana a sus superiores detallando los hechos. ${ }^{51}$

La noche del asalto había treinta personas pernoctando en la posada y sus inmediaciones y dos arrías de mulas cargadas, más cuatro guardas de la aduana. Repentinamente se escuchó un tropel de caballos, imprecaciones y varios tiros ingresaron por las ventanas. Los guardas decidieron rendirse y entregar sus revólveres a los montoneros que tenían rifles modernos. Apenas rendidos, dos de ellos empezaron a golpear a un guarda con un sable y son contenidos por quien se presentó como el coronel Santos Guayama. Luego de hacerlos atar, preguntó a cada uno "su nombre, patria y profesión”. "Al saber que éramos empleados nos llenó de improperios, tratándonos de bandidos, ladrones" y les exigió la exhorbitante suma de 3 mil pesos por su vida. Guayama descubrió enseguida el dinero de la aduana, 80 pesos en plata boliviana. Al saber que era de la aduana, comentó con el mayor cinismo, según el guarda, "Pues este dinero es mío como todo lo que pertenece al gobierno nacional y provincial". Luego de interceder en negociaciones con el caudillo, que redujo el rescate de los guardas a 500 pesos, los viajeros y dueños de arrias reúnen el dinero. Después Guayama,

[S]e despidió muy galantemente, brindándonos con su amistad y exigiéndonos que le escribiéramos a cualesquier punto donde él se hallase, exhortándonos a que siguiéramos su buena causa: denigró la conducta del Gobierno Nacional como a todos sus jefes [...] nos dijo finalmente que se iba a Chile pero que luego oiríamos resonar su nombre por el lado en que nace el sol.

51 Documento importante. El Constitucional, 16 de abril 1872.
A los pocos minutos de irse Guayama, su capitán "hombre de bastante mal aspecto" entra al cuarto de los prisioneros y le espeta al guarda: "Ud. es el Comandante Don Camilo Lemos, ¿no te acuerdas de cuando me tomastes en Las Lagunas y me quitastes el tordillo? ¿Qué lo has hecho, ladrón?”, y dio orden de atarlo para matarlo. Lemos, que había cambiado su nombre, pensó que "aquellos forajidos buscaban [...] saciar su sed de sangre matándonos a todos". Nuevamente uno de los comerciantes llama a Guayama y lo convence de que no mate a Lemos, aduciendo que era otra persona. En el momento de terror el guarda, sostén de una familia con varios hijos pequeños se queja que a pesar de sus servicios al Estado "ni aún el amo a quien sirvo hace catorce años [...] se acordará de ellos, dejándolos perecer sin compasión; sí, señor, esa es la triste perspectiva que tenemos a la vista los empleados de la Aduana Nacional; yo iba a morir por la sola culpa de ser Guarda Nacional". A lo largo de la noche, montoneros que parecen moverse con gran libertad respecto de las órdenes de su jefe, borrachos, iracundos, peleándose entre ellos, persiguen a caballo y disparan repetidas veces al guarda que extrańamente logra escapar a pie luego de ser atrapado y a punto de ser degollado. Los montoneros no agredieron ni pidieron rescate a ninguno de los casi 30 viajeros y peones, quitándoles solamente algunas mulas y pequeños efectos.

El relato del guarda revela algunos aspectos centrales del discurso y actitudes de Guayama. Lo primero que llama la atención es la intención de dar legitimidad de sus actos y su obsesión con las figuras de gobierno y la burocracia estatal. Pese a que el narrador quiere instalar la monstruosidad del caudillo su propio relato socava esta imagen. En su trato se muestra irónico pero respetuoso y no ejerce ninguna violencia directa, aunque es bastante obvio su rol negociador en contraposición a la barbarie desplegada por sus hombres. Desechando el presumiblemente abundante botín representado por los bienes de los comerciantes y viajeros, se contenta con el dinero de la aduana y el rescate de los guardas, tal vez para calificar como beligerante político y no como salteador frente a potenciales propagandistas. Pese a sus amenazas, no asesina a nadie y acepta rebajar muy significativamente el rescate exigido. Más allá 
del carácter ridículo que el guarda intenta conferirle, Guayama tiene un discurso político y publicita una causa que presenta como justa, la reivindicación de una autoridad o soberanía usurpada por los actuales gobiernos. Esto se expresa en la limitación del robo sobre los fondos de la aduana, y su declaración de que el dinero y bienes de los gobiernos nacional y provincial le pertenecen y no solo cuestiona a las cabezas del gobierno sino a toda su estructura, incluyendo a los propios guardas a quienes acusa de bandidos y ladrones. Esto es reforzado por la imputación del capitán de Guayama al guarda de ladrón por haberle robado un caballo.

El relato del guarda parece reproducir fielmente los hechos y el discurso del caudillo. Se reconocen términos de las cartas que hemos citado sobre el pacto de amnistía a los montoneros luego de la toma de La Rioja, donde se presentan como autoridades legítimas vulneradas rechazando el mote de "montoneros rebeldes contra las autoridades de la República y de la Provincia" y "creyendo hacer uso de un derecho legítimo y rendir un servicio a la causa pública y aun al gobierno mismo de la Nación". La falta de reconocimiento estatal y el fracaso de su incorporación burocrática es presentada como el principal motivo de la reanudación de las hostilidades. Más aún, el documento cuestionaba la destitución de los montoneros de sus cargos como un problema de gobierno en la campaña ya que habrían quedado "las plazas en acefalia y sin autoridades locales".

Guayama en el fondo parece querer ser él también un "empleado" y desear más los cargos y su legitimidad que el dinero. Él y sus hombres parecen actuar, así, como "patrullas perdidas" burocrático-militares en procura del Estado, sin más representatividad que la voluntarista proclama de ser él mismo el gobierno nacional. Sin embargo, el eco de esta soberanía posible resonaba en las primeras décadas del siglo XX. Según el escritor y folclorista Ezequiel Ortiz Ponce (1953, p. 83) un viejo criollo aún cantaba sobre "el levantamiento del cacique Guayama [...] para recuperar para los nativos las provincias de San Luis, Mendoza y San Juan":

El veinticuatro de abril

a las cuatro 'e la mañana

se oyeron los cańonazos del gran general Guayama.

\section{Conclusión}

Pese a la consideración anárquica de las rebeliones montoneras de la segunda mitad del siglo XIX, la insurrección lagunera puede entenderse como una resistencia estatal y republicana en diversos sentidos. Primero, porque se arraigaba en una tradición política y jurídica local que había articulado instituciones de gobierno, representación política y mediación estatal local en un contexto de ausencia o trabajosa construcción de un estado organizado y legítimo. Esta institucionalidad estatal y a la vez comunitaria, era deudora de una experiencia colonial previa de demandas, adaptación y creación política indígenas, entendiendo como tal calificativo no a la preexistencia de un "grupo étnico" sino al núcleo de legitimación de intereses colectivos, la adscripción identitaria y la jurisprudencia invocada en sus demandas.

Segundo, porque si bien esta experiencia estatal fue en gran medida derrotada por un nuevo proceso colonial republicano hacia las décadas de $1860 \mathrm{y}$ 1870 , hasta último momento pugnaron por el reconocimiento de estas tradiciones y autoridad y su incorporación burocrática en la estructura del nuevo sistema de Estado, intentando preservar sus derechos territoriales indígenas. Los laguneros parecen haber construido o reclamado estatidad de un modo consistente y continuo, negociando demandas con los poderes del gobierno provincial; derechos, autonomía y justicia, o movilizándose militarmente. La insurrección de Guanacache, en la que se inserta Guayama como referente visible, se explica en gran medida por la crisis -luego de la derrota del ejército y gobiernos federales-, de los canales de negociación por las tierras, derechos e incorporación estatal que habían estado operativos para los laguneros desde principios del período independiente.

La guerra sin embargo, como el propio discurso de Guayama sugiere, no fue necesariamente considerada una "revolución" contra el gobierno o la go- 
bernabilidad, sino como un recurso necesario para salvaguardar una legitimidad política previa. Las autoridades locales, que lo fueron también del gobierno provincial en comunidades que todavía eran catalogadas como "reducciones", habían aportado apoyo militar a cambio de autonomía desde la formación del Ejército de los Andes del general San Martín y a lo largo de las guerras civiles. Esta participación (como en general la relativa lealtad política al gobierno provincial) había estado ligada a demandas por el respeto y legalización de la propiedad de sus tierras en tanto indios. En cierto modo las aspiraciones y discursos de los funcionarios locales, jueces, comisarios y subdelegados fueron continuadas por Guayama por una vía insurreccional y retomadas con posterioridad a su muerte.

\section{Referencias citadas}

Acevedo, E. O. (1979). Orígenes de la organización judicial de Mendoza. Mendoza: Fundación para la Educación, la Ciencia y la Cultura.

Archivo del General Mitre, Tomo XII. Pacificación y reorganización nacional después de Pavón (conclusión) (1912). Buenos Aires: Biblioteca de la Nación.

Ardissone, R. y Grondona, M. F. (1957). La instalación aborigen en Valle Fértil. Buenos Aires: Instituto de Geografía, FFyL, Universidad Nacional de Buenos Aires.

Arias, D. (s.d.). (Mimeo). Santos Guayama, esfinge de una época y una estirpe.

Bernabéu, S., Giudicell Ch. y Havard, G. (Comps.). (2012). La Indianizacion. Cautivos, renegados, "hommes libres" y misioneros en los confines americanos. Madrid: Doce Calles.

Bragoni, B. y Míguez, E. (2010). Un nuevo orden político. Provincias y Estado Nacional 1852-1880. Buenos Aires: Biblos.

Brnasboin, H. (2015). Mendoza federal. Entre la autonomía provincial y el poder de Juan Manuel de Rosas. Buenos Aires: Prometeo.

Carte, E. (1969). Las varias muertes de Santos Guayama. Todo es Historia, 23, 36-45.
Chiaramonti, G. (2005). A propósito del debate HerreraGálvez de 1849: Breves reflexiones sobre el sufragio de los indios analfabetos. En Historia de las elecciones en el Perú. Aljovín de Losada, C. y López, S. (Comps.). Lima: Instituto de Estudios Peruanos.

Chumbita, H. (1994). Martina Chapanay, bandida y montonera. Todo es historia, 33, 36-42.

Chumbita, H. (1998). Los rebeldes de Santos Guayama. Todo es historia, 368, 70-88.

Chumbita, H. (2000). Jinetes rebeldes, Historia del bandolerismo social en la Argentina. Buenos Aires: Vergara.

Concatti, R. (2003). El tiempo Diablo del Santo Guayama. Mendoza: Corregidor.

Cunill, C. (2011). El indio miserable: Nacimiento de la teoría legal en la América colonial del siglo XVI. Cuadernos Intercambio, 9, 229-248.

De Ahumada, M. (1860). Código de las Leyes, Decretos y Acuerdos que sobre Administración de justicias se ha dictado la Provincia de Mendoza. Mendoza: Imprenta El Constitucional.

De la Fuente, A. (2000). Childrens of Facundo. Durham: Duke University Press.

Díaz, A., Ruz, R. y Galdames, L. (2011). Participación de la población indígena en la política y justicia comunitaria en Arica y Tarapacá durante el siglo XIX. Revista de Estudios Históricos-Jurídicos, 33, 511-532.

Escolar, D. (2007). Los dones étnicos de la Nación. Identidades huarpe y modos de producción de soberania en Argentina. Buenos Aires: Prometeo.

Escolar, D., (2013). Huarpes Archives in the Argentine Desert: Indigenous Claims and State Construction in Nineteenth-Century Mendoza, 93(3), August, 2013, 451-483.

Escolar, D., (2015). Jueces indígenas, caciques criollos: autonomía y estatalidad en Guanacache, Mendoza (siglo XIX). Tiempo Histórico, 9, 37-72. Universidad Academia de Humanismo Cristiano, Chile.

Estrada, M. (1962). Martina Chapanay, realidad y mito. Buenos Aires: Imprenta Varese. 
Fandos, F. y Teruel, A. (2008). Procesos de privatización y desarticulación de tierras indígenas en el norte de Argentina en el siglo XIX. Revista Complutense de Historia de América, 35, 233-255.

Fradkin, R. (2006). La historia de una montonera. Buenos Aires: Siglo XXI.

Funes, L. (1938). Guallama. Revista de la Junta de Estudios Históricos de Mendoza XI, 25-26, 151-160.

García, A. (2004). Tras las huellas de la identidad huarpe. Mendoza: Facultad de Filosofía y Letras, Universidad Nacional de Cuyo.

Godoy Orellana, M. y Contreras Cruces, H. (2007). Tradición y modernidad en una comunidad indigena del Norte Chico: Valle Hermoso, siglos XVII al XX. Santiago: Editorial Universidad Bolivariana.

Igarzábal, Rafael. (1873). La Provincia de San Juan en la Exposición de Córdoba. Geografía y Estadistica. Buenos Aires, s.e.

Isla, A. (2002). Los usos politicos de la identidad. Indigenismo y Estado. Buenos Aires: Editorial de las Ciencias.

Larraín, N. (1906). El País de Cuyo. Relación histórica hasta 1872. Buenos Aires: Imprenta de Juan A. Alsina.

López, C. (2006). Tierras comunales, tierras fiscales: el tránsito del orden colonial a la revolución. Anuario del CEIC 3, La propiedad de la tierra, pasado y presente, 3967.

Lorandi, A. M. (1992). El mestizaje interétnico en el noroeste argentino. En Tomoeda, H. y Millones, L. (eds.), 500 años de mestizaje en los Andes (pp. 133-166). Osaka: National Museum of Ethnology.

Lorandi, A. M. (Comp). (1997). El Tucumán colonial y Charcas. Buenos Aires: Facultad de Filosofía y Letras, Universidad de Buenos Aires.

Massini Calderón, J. L. (1967). Mendoza hace 100 años. Historia de la provincia durante la presidencia de Mitre. Buenos Aires: Theoría.

Maza, J. I. (1980). Ensayo sobre la historia del Departamento de Lavalle. Mendoza: Editorial Estudio Alfa.
Méndez, C. (2005). The Plebeian Republic. The Huanta Rebellion and the Making of Peruvian State, 1820-1850. Durham \& London: Duke University Press.

Métraux, A. (1937). Contribución a la etnografía y arqueología de la Provincia de Mendoza. Revista de la Junta de Estudios Históricos de Mendoza. Tomo VI, 15 y 16, 1-66.

Michieli, C. (2000). La disolución de la categoría jurídicosocial de "indio" en el siglo XVIII: El caso de San Juan (Región de Cuyo). San Juan: Publicaciones de la Universidad Nacional de San Juan, Facultad de Filosofía, Humanidades y Artes, Instituto de Investigaciones Arqueológicas y Museo, 23.

Michieli, C. (2004). La Fundación de Villas de San Juan (siglo XVIII). Buenos Aires: Sociedad Argentina de Antropología.

Ortiz Ponce, E. (1953). Mendoza Legendario. Mendoza: D'Accurzio.

Otero, H. (2006). Estadistica y Nación: una historia conceptual del pensamiento censal de la Argentina Moderna 18691914. Buenos Aires: Prometeo.

Paz, G. L. (1991). Resistencia y rebelión campesina en la puna de Jujuy, 1850-1875. Boletín del Instituto de Historia Argentina y Americana Dr. Emilio Ravignani, III (4), 63-89.

Paz, G. L. (2005). Liderazgos étnicos, caudillismo y resistencia campesina en el norte argentino a mediados del siglo XIX. En Goldman, N. y Salvatore, N. (Comps.). Caudillismos Rioplatenses. Nuevas Miradas a un Viejo Problema (pp. 310-346). Buenos Aires: Eudeba.

Paz, G. L. (2008). Los pueblos de indios del Tucumán colonial revisitados: De la desestructuración a la identidad. Andes, 19, 213-224.

Paz, G. L. (2009). El “comunismo” en Jujuy: ideología y acción de los campesinos indígenas de la puna en la segunda mitad del siglo XIX. Nuevo Mundo Mundos Nuevos, Débats, décembre.

Prieto, M. D. R. (2000). Formación y consolidación de una sociedad de frontera en un área marginal del Reino de Chile: La provincia de Cuyo en el siglo XVII. Anales de 


\section{Arqueologia y Etnología, 52-53.}

Quiroga de Yakin, J., (1971). Vida de Santos Guayama; San Juan: Editorial Sanjuanina.

Quiroga Salcedo, C. E. y González de Ortiz, A. E. (1987). El Terremoto de San Juan del 27 de Octubre de 1894. San Juan: Facultad de Filosofía, Historia y Arte, Universidad Nacional de San Juan.

República Argentina, Primer Censo 1869.

Rock, D. (1998). Civil war in nineteenth century Argentina: San Juan 1860-1861). MacFarlane, A. \& Wiesebron, M. L. (Comps.). Cuadernos de AHILA, Asociación de Historiadores Latinoamericanistas Europeos, 4.

Rodríguez, L. (2010). "Informar si el padrón que rige se conocen dos pueblos de Amaicha”. Reestructuraciones socio-étnicas y disputas por tierras entre la Colonia y la República. Memoria Americana, 18(2), 267-292.

Sanjurjo, I. (2004). La organización politico-administrativa de la campaña mendocina en el tránsito del antiguo régimen al orden liberal. Buenos Aires: Instituto de Investigaciones de Historia del Derecho.

Sarmiento, D. F. (1869). Cartas con las vistas y propósitos de Don Manuel Taboada. Buenos Aires: Imprenta Argentina de El Nacional.

Sarmiento, D. F. (1902). Papeles del Presidente 1868-1874, parte primera, L. Buenos Aires, s.d.

Sarmiento, D. F. (1947 [1867]). Vidas de Fray Félix Aldao y El Chacho. Buenos Aires: Argos.

Sarmiento, D. F. (1963 [1845]). Facundo. Buenos Aires: Losada.

Siri, J. M. (1945). Guayama. Boletin de la Junta de Historia de la Provincia. San Juan, 8, 75-88.

Tamagnini, M. (2007). Conflictividad y violencia en la frontera sur de Córdoba. Malones y montoneras en la década de (1860). En Rocchietti, A. M. y Tamagnini, M. (Comps.). Arqueología de la Frontera: Estudios sobre los campos del sur cordobés (pp. 15-70). Río Cuarto: Universidad Nacional de Río Cuarto.
Tell, S. (2010). Expansión urbana sobre tierras indígenas. El pueblo de La Toma en la Real Audiencia de Buenos Aires. Mundo Agrario, 1-31.

Torre Revello, J. T. (1939). La población de Cuyo a principios del período independiente, 1777 y 1812 . Boletín del Instituto de Investigaciones Históricas, 77-78, T.2, 77-84.

Verdaguer, J. A. (1931). Historia eclesiástica de Cuyo, vol. I. Milano: Premiata Scuola Tipográfica Salesiana.

Videla, H. (1989). Historia de San Juan, Tomo VI (Época patria) 1875-1914. Buenos Aires: Universidad Católica de Cuyo.

Vignati, M. A. (1953). Aportes al conocimiento antropológico de la Provincia de Mendoza III. Diario de viaje por las Lagunas en el año de 1789. Notas del Museo de Eva Perón XVI (57), 51-103.

Zubrzycki, B., Maffia, M. y Pastorino, L. (2003). La propiedad de la tierra y el agua en el noroeste argentino. El caso de los campos comuneros en el Valle de Hualfin. Estudios Atacameños, 25, 103-116.

\section{Fuentes primarias consultadas}

Archivo Histórico de Mendoza

Archivo de Domingo Faustino Sarmiento

Archivo Histórico Mitre

Archivo de Juan Nievas

Archivo del General Mitre. Pacificación y Reorganización Nacional después de Pavón (Conclusión) (Tomo XII). Buenos Aires: Biblioteca de la Nación.

Diario El Constitucional

Encuesta Nacional de Folklore 1921 